\title{
Earthquake Preparedness in Schools of Islamabad
}

\author{
Nadia Tariq ${ }^{1}$, Tamkeen Jaffry', Sadaf Khalid ${ }^{1}$ \\ ${ }^{1}$ Assistant Professor, Department of community Medicine, Islamabad Medical and Dental College
}

\begin{abstract}
Background: Pakistan is located in the Himalayan region, which has the highest vulnerability to earthquakes. The IslamabadRawalpindi area lies in a tectonically active zone, where earthquakes have been frequent in the recent geological past. Earthquake preparedness in schools is relatively under studied area in Pakistan. The objective of this study was to determine the level of preparedness of schools for earthquakes and to compare it between urban and rural, government and private schools in Islamabad Capital Territory.

Material and Methods: It was a cross-sectional comparative study. The study population was schools of Islamabad Capital Territory. The total sample size was 74 and non-probability purposive sampling technique was used. Data was collected through a structured questionnaire pretested on $5 \%$ of the sample size and respondents were administrative staff of schools. Data was analyzed using SPSS version 21. Data of the categorical variables was presented in the form of frequencies (percentages). Statistical significance of association between school profile and level of preparedness was determined by using bivariate tabular association analysis (Chi square).

Results: Out of 74 schools, 61 were private and 14 were government schools. 46 schools were located in urban areas while 28 were in rural area of Islamabad Capital Territory. Out of the total schools, $66.2 \%$ had written preparedness plan for earthquake and $73 \%$ of the schools had a safety committee to lead disaster response planning. Most of the schools (82.4\%) had minimum of two exits in high occupancy rooms. There was significant association of location of school with preparedness plan for earthquake $(p=0.009)$, and type of school with two evacuation drills annually $(p=0.03)$.

Conclusion: Private schools and those located in urban areas are better prepared for earthquakes as compared to government schools and the ones located in rural areas.

Key words: Earthquake, Emergency Preparedness, Schools

Authors' Contribution:

${ }^{1}$ Conception, synthesis, planning of research Nadia Tariq

Article info:

and manuscript writing Interpretation,

discussion, Active participations in data

Email: nadia.tariq@imdcllege.edu.pk

Received: June 26, 2019

Accepted: August 19, 2019

collection and Data analysis.

Cite this article. Tariq N, Jaffry T, Khalid S. Earthquake Preparedness in Schools of

Islamabad. J Islamabad Med Dental Coll.2019; 8(3):141-145. doi 10.35787/jimdc.v8i3.398

Funding Source: Nil

Conflict of Interest: Nil
\end{abstract}

\section{Introduction}

Natural disasters around the world kill an average of 74,000 and affect more than 230 million people annually. ${ }^{1}$ Many natural disasters, earthquakes, tsunamis and hurricanes are the deadliest; responsible for loss of lives and damage to properties. ${ }^{1}$ They put a huge burden on the economy. There is a long history of catastrophic earthquakes throughout the world, which usually occur with little or no warning. ${ }^{2}$ United States and Japan are most prone and have experienced frequent earthquakes in the last 20 years. ${ }^{3}$
Pakistan is located in a Zone roughly $200 \mathrm{~km}$ north of the Himalaya Front. This region has the highest vulnerability to earthquakes. ${ }^{4}$ The resistance of the buildings determines amount of loss to a great extent. The poor standard of buildings in Pakistan indicates a major seismic risk. Seismic vulnerability manifests itself most intensely in building collapses, falling objects and inadequate emergency exits. ${ }^{5}$

The educational system of Pakistan comprises of preprimary, primary, middle, high, high secondary schools, inter colleges and degree colleges. Islamabad 
has total of 1105 private and 348 government institutes from preprimary level till high school. ${ }^{6}$ A school is a foundation that houses a community's future. The collapse of a school in a community has more psychological impact as compared to other buildings. School's distinct structural and managerial characteristics make them vulnerable to earthquakes. The main causes behind the greater vulnerability of schools are poor building construction practices, lack of good supervision and quality control, lack of financial resources and lack of awareness and understanding about the risks and possibility of mitigation measures. ${ }^{7}$

The Islamabad-Rawalpindi area lies in a tectonically active zone, where earthquakes have been frequent in the recent geological past. On October 28, 2010 earthquake jolts were felt in different areas of Khyber Pakhtunkhwa, Punjab, Azad Kashmir and Islamabad. ${ }^{8}$ Approximately, 1,500 people were rendered homeless. The 2005 Pakistan earthquake resulted in extensive damage in Azad Jammu Kashmir and eastern districts of Khyber Pakhtunkhwa. It killed more than 80,000 people in Pakistan, resulted in the collapse of 8000 schools in the North-West part of the country taking an indescribable toll on children. ${ }^{9}$ Each time a disaster occurs, a large number of school children are victimized. Our children are the future; their school buildings must be safe in the face of natural hazards and children must be enabled with an understanding of natural hazards and actions they can take to be in a better position to face the next "incident". With respect to natural hazards, educational institutions have a multiple role to ensure the safety of their students, teaching them about natural hazards and planning for disaster prevention in future. ${ }^{10}$

Teachers are the first line responders in case of disaster. It is important to train school administrators to prepare for disaster in school with the defined role of each staff member during and after the event. In addition to that, there is a need to prepare disasters awareness programs for the community utilizing experiences of other developed countries in disasters and emergencies management especially for school. ${ }^{11}$

Preparedness is a continuous cycle of planning, organizing, training, equipping, exercising, evaluating and taking corrective action. ${ }^{12}$ The rationale behind this study was Earthquake preparedness in schools is relatively under studied area in Pakistan. Implementation of preparedness measures in schools can significantly reduce damage. Objectives of this study were firstly to determine level of preparedness of schools for earthquakes and secondly to compare preparedness between urban/ rural and government/ private schools respectively.

\section{Material and Methods}

A cross sectional comparative study was carried out in schools of Islamabad Capital territory. Out of total 1453 schools $^{6}$ (Government:348, Private:1105), calculated sample size was 74 with $80 \%$ confidence level, absolute precision $5 \%$ and design effect of $0.5^{13}$ Sample size was calculated using the following formula $\left(n=\left[\operatorname{DEFF}{ }^{*} N p(1-p)\right] /\left[\left(d^{2} / Z^{2} 1\right.\right.\right.$-al $\left.\left.{ }^{*}(N-1)+p^{*}(1-p)\right]\right)$. Schools were selected on the basis of non-probability purposive sampling technique. Inclusion criteria was PrePrimary, Primary, Middle and High schools (Government and Private) located in commercial as well as residential areas whereas Madrassas, Vocational Institutes and Tuition centers were excluded. Study was carried out from July, 2018 till December, 2018. A self-designed structured questionnaire was used, pretested on $5 \%$ of the sample size and modified accordingly. The content of the questionnaire included information on school profile like location of the school, its general condition, type and educational level, conforming to standard building codes etc. In addition, there was a checklist of various measures related to preparedness for earthquakes. ${ }^{14-17}$ Reliability analysis of questionnaire was carried out. Cronbach's alpha showed acceptable reliability at 0.79 . Respondents were the key informants assigned by the school administration. Data was analyzed using SPSS version 21. Data of the categorical variables was presented in the form of frequencies (percentages). Statistical significance of association between school profile and level of preparedness was determined by using bivariate tabular association analysis (Chi square).

Technical and ethical approval from Institutional Review Board was taken. In addition, informed written consent from the school administrator/Principal was taken and 
confidentiality was maintained throughout and after the study.

\section{Results}

Out of 74 schools, 61 were private and 14 were government. 46 schools were located in urban areas while 28 were in rural area of Islamabad Capital Territory (ICT). The level of 13 schools was pre-primary or primary while19 were middle and 42 were high schools. Most of the schools had double $(42.9 \%, \mathrm{n}=24)$ or triple storey (23.2\%, $n=13)$ buildings. Maximum (91.4\%, $n=64)$ number of the schools were built according to the standard building codes. Remaining were either not built according to building codes or the informant did not have the information.

Most of the schools $(66.2 \%, n=49)$ had written preparedness plan for earthquakes and staff was aware of their roles and responsibilities. About $73 \% \quad(n=54)$ schools had a safety committee to lead disaster response planning. Regular meetings in $54.1 \%$ schools $(n=40)$ included staff as well as students. Parents were not included in these meetings in most of the schools $(74.3 \%$, $n=55)$ and community leaders were also not the part of the meetings in the majority of schools $(73 \%, n=54)$.

A detailed map of the school was displayed in only 39 school and building exit routes were marked in 40 schools. Most of the schools $(79.7 \%, n=59)$ did not have an automatic emergency lighting. High occupancy rooms had minimum of two exits in $82.4 \%(n=61)$ schools, while only 43 schools had exit doors that opened outwards. There was no separate route of evacuation for disabled students in $94.1 \%$ schools $(n=64)$ (Figure 1). Awareness among teachers regarding measures to be taken before, during and after an Earthquake is shown in Table I.

42 schools had minimum of two building evacuation drills with each class annually. There was no trained staff for search and rescue in $52.7 \% \quad(n=39)$ schools, while location of main gas, electricity and water shut off valves was known to staff of $83.8 \%(n=62)$ schools. Evacuation plan was shared with nearest police station in 51 schools while 38 had shared it with nearest fire station and 36 schools with the nearest hospital, respectively.

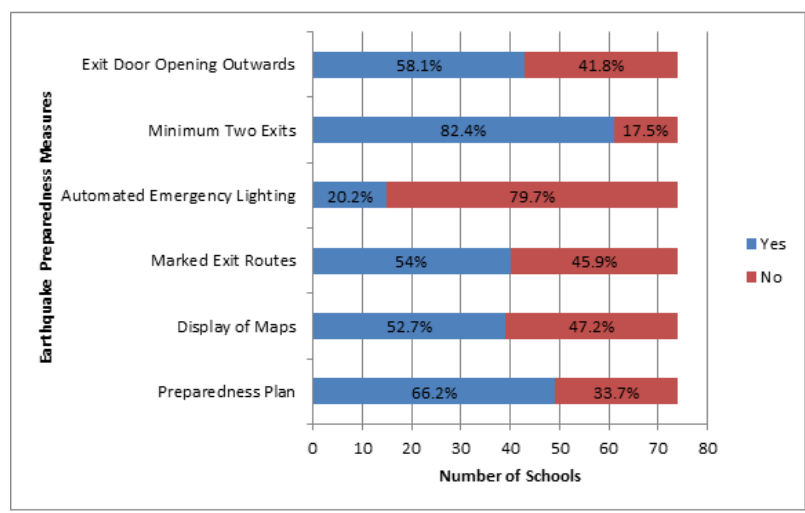

Figure 1: Earthquake Preparedness Measures observed in different Schools.

\begin{tabular}{|l|c|c|}
\hline \multicolumn{3}{|c|}{$\begin{array}{c}\text { Table I: Schools with Awareness among teachers regarding } \\
\text { measures to be taken before, during and after an Earthquake } \\
\text { (n=74) }\end{array}$} \\
\hline $\begin{array}{l}\text { Awareness among teachers about measures for } \\
\text { earthquake preparedness }\end{array}$ & Yes & No \\
\hline Implementing Duck and cover Action & 59 & 15 \\
\hline $\begin{array}{l}\text { Having Emergency kit near students' desk and } \\
\text { release information near the desk }\end{array}$ & 23 & 51 \\
\hline $\begin{array}{l}\text { When to Evacuate and when to remain in class } \\
\text { room }\end{array}$ & 63 & 11 \\
\hline How to administer First Aid & 56 & 18 \\
\hline Working in buddy system & 39 & 35 \\
\hline
\end{tabular}

There was significant difference between urban and rural schools in display of map $(p=0.00)$, having marked exit routes $(p=0.00)$, having automatic emergency lighting $(p=0.025)$, exit doors opening outwards $(p=0.03)$, display of standard operating procedures $(p=0.00)$,awareness of teachers about duck and cover action $(p=0.00)$, having staff trained for search and rescue $(p=0.03)$, sharing of evacuation plan with nearest police station $(p=0.00)$ and having buildings built according to standard building codes $(p=0.02)$.

There was significant difference between government and private schools in level of preparedness as shown in Table II.

\section{Discussion}

This study done in schools of Islamabad Capital Territory reveals, that most of the schools whether government or private have written preparedness plan for earthquakes and a safety committee to lead disaster response planning. 


\begin{tabular}{|l|c|c|c|c|c|}
\hline \multicolumn{5}{|c|}{ Table II: Preparedness Measures According to Type of School } \\
\hline Variables & \multicolumn{2}{|c|}{ Government } & \multicolumn{3}{|c|}{ Private } \\
\cline { 2 - 6 } & Yes (\%) & No (\%) & Yes (\%) & No (\%) & \multicolumn{2}{|c|}{$\boldsymbol{P}$ value } \\
\hline Schools in having written preparedness plan & 33.3 & 66.7 & 70.8 & 29.2 & 0.02 \\
\hline Display of map in schools & 11.1 & 88.9 & 58.5 & 41.5 & 0.00 \\
\hline Exit doors opening outwards & 22.2 & 77.8 & 63.1 & 36.9 & 0.02 \\
\hline Display of standard operating procedures & 0 & 100 & 35.9 & 64.1 & 0.02 \\
\hline $\begin{array}{l}\text { Awareness of teachers regarding implementation of duck and } \\
\text { cover action }\end{array}$ & 33.3 & 66.7 & 86.2 & 13.8 & 0.00 \\
\hline Having minimum of two evacuation drills annually & 88.9 & 11.1 & 52.3 & 47.7 & 0.03 \\
\hline Sharing of evacuation plan with nearest police station & 11.1 & 88.9 & 78.1 & 22.9 & 0.00 \\
\hline Sharing of evacuation plan with nearest hospital & 11.1 & 88.9 & 54.7 & 45.3 & 0.01 \\
\hline
\end{tabular}

This is in accordance with a study conducted in Turkey ${ }^{18}$ where school administrators had pre-disaster plan for earthquakes with noticeable differences between the status of school preparedness and school type. High schools were better prepared than elementary schools. The schools located in cities were better prepared as compared to the ones located in villages. Our study also showed significant difference between Government/Private and Rural/Urban schools in having preparedness plan for earthquakes. While there was no significant association between educational level of school and having earthquake preparedness plan.

The results of this study show that the schools have minimum of two exit routes in high occupancy rooms with exit doors opening outwards, which is in accordance with the standard criteria ${ }^{16}$ but maps showing the exit routes are displayed in half of the total schools of our study. It is very important to display maps showing evacuation route at all the levels of the school building.

For years, experts have said that if there is an earthquake, we should Duck, Cover and Hold i.e. Duck under something strong like a desk, then stay under cover and hold on until the shaking stops. Our study results are encouraging showing almost $80 \%$ school teachers know about this measure. The official earthquake protection instructions for schools and kindergartens in Israel have recently been updated from the traditional "drop, cover and hold on" approach to the "flee outside to an open space" approach. ${ }^{19}$

Earthquake and safety drills have a good effect on enhancing preparedness at the time of earthquake and improving safety culture. As earthquakes come without warning, unpreparedness among teachers, students and other staff may result in trauma and casualties. ${ }^{20}$ This study shows almost half of the schools practice recommended two evacuation drills annually along with its evaluation at the end of the year.

Circumstances requiring medical attention are common at schools. According to a study conducted in South India, poor and moderate knowledge of first aid was observed among $13 \%$ and $87 \%$ teachers, respectively. In contrast, $75.7 \%$ schools included in this study had teachers who knew how to administer first aid to the seriously wounded, which is very important as teachers are often the first individuals to witness and handle situations requiring first aid and medical emergencies. ${ }^{21}$

\section{Conclusion}

Majority of schools of Islamabad, especially private and those located in urban areas are well prepared for earthquakes. Government should take measures to strengthen it further in private schools; however major steps should be taken to improve earthquake preparedness in government schools, as well as those located in rural areas.

\section{References}

1. TuladharG, Yatabe R, Dahal RK, Bhandary NP. Knowledge of disaster risk reduction among school students in Nepal. Geomatics, Natural Hazards and Risk. 2013; 5(3): 190-207. Doi: 10.1080/19475705.2013.809556 
2. Dixit AM, Yatabe R, Dahal RK, Bhandary NP. Public School Earthquake Safety Program in Nepal. Geomatics, Natural Hazards and Risk. 2014; 5(4): 293-319. Doi: 10.1080/19475705.2013.806363

3. Alex Greer M S. Earthquake preparedness and Response: Comparison of United States and Japan. Leadership and Management in Engineering. 2012; 12(3). Doi:10.1061/(ASCE)LM.1943-5630.0000179

4. Iqal A. Pakistan in the most active quake zone, says US geological survey. Dawn News. 2015.

5. Rafi MM, Lodi SH, Ahmed M, Kumar A, Verjee F. Development of building inventory for northern Pakistan for seismic risk reduction. International Journal of Disaster Resilience in the Built Environment. 2016; 7(5): 501-20.

6. Pakistan education statistics. National Education Management Information System. Ministry of Federal education. Government of Pakistan. 2015-16. http://library.aepam.edu.pk/Books/Pakistan\%20Educa tion\%20Statistics\%202015-16.pdf last cited on 8-818.

7. Rodgers JE. Why schools are vulnerable to earthquakes. In Proceedings, 15th world conference on earthquake engineering, Lisbon. 2012. (pp. 24-28).

8. M 7.7-61km NNE of Awaran, Pakistan, 2013-09-24 11:29;47(UTC).USGeologicalSurvey.earthquake.usgs .gov. accessed on 18-7-19.

9. Rehman K. Analysis of the devastating Kashmir earthquake 2005 aftershocks. Arabian Journal of Geosciences. 2016; 9: 379. Doi: 10.1007/s12517016-2418-6

10. Tuladhar G, Yatabe R, Dahal RK, Bhandary NP. Knowledge of disaster risk reduction among school students in Nepal, Geomatics, Natural Hazards and Risk.2013; 9(3): 190-207. Doi: 10.1080/19475705.2013.809556

11. Margolin G, Ramos MC, Guran EL. Earthquakes and children: The role of psychologists with families and communities. Professional Psychology: Research and Practice. 2010; 41(1): 1-9. Doi: 10.1037/a0018103

12. Park K. Disaster management. Preventive and social medicine.2014: 740-747.

13. Kevin M. Sullivan, John C. Pezzullo, Andrew G, Roger A. Mir. Sample size calculator. Open Source Statistics for Public health. http://www.openepi.com/SampleSize/SSCohort.htm. Accessed on 1-7-2018

14. Disaster and Emergency preparedness: Guidance for schools. International Finance Corporation, World Bank. 2010: 6-41.

15. Tatebe J, Mutch C. Perspectives on education, children and young people in disaster risk reduction. International Journal of Disaster Risk Reduction.2015; 14(2): 108-114. Doi: 10.1016/j.ijdrr.2015.06.011

16. Twig J. Disaster Risk Reduction. Good practice Review. 2015; 9: 2-17.

17. Dixit A M, Yatabe R, Dahal R K Bhandary,N P. Public School Earthquake Safety Program in Nepal. Geomatics, Natural Hazards and Risk. 2014; 5(4). Doi: 10.1080/19475705.2013.806363

18. Ocal A, Topkaya Y. Earthquake preparedness in schools in seismic hazard regions in the South-East of Turkey. Disaster Prevention and Management.2011; 20(3): 334-348. Doi: 10.1108/09653561111141754

19. Rapaport, C. and Ashkenazi, I. "Drop down or flee out?". International Journal of Disaster Resilience in the Built Environment. 2019; 10(1): 52-64. https://doi.org/10.1108/IJDRBE-09-2018-0040

20. Izadkhah YO, Hosseini KA. An Evaluation of Disaster Preparedness in Four Major Earthquakes in Iran. Spring and Summer.2010; 12(1): 62-75.

21. Joseph N, Narayanan T, Zakaria SB, Nair AV. Awareness, attitudes and practices of first aid among school teachers in Mangalore, South India. Journal of primary health care. 2015; 7(4): 274-281. 